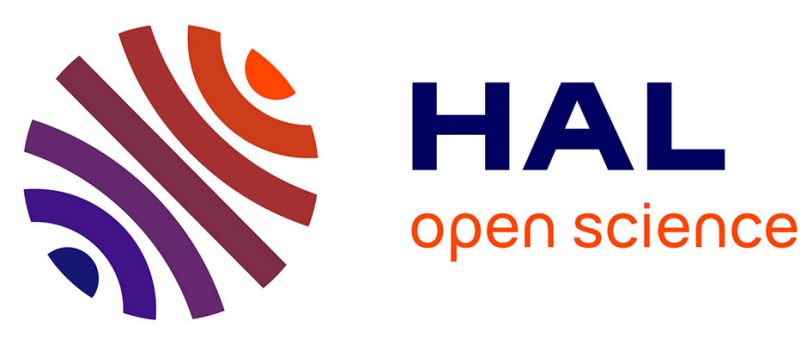

\title{
Mass nouns and plural logic
}

David Nicolas

\section{To cite this version:}

David Nicolas. Mass nouns and plural logic. Linguistics and Philosophy, 2008, 31 (2), pp.211-244. 10.1007/s10988-008-9033-2 . ijn_00130930v4

\section{HAL Id: ijn_00130930 https://hal.science/ijn_00130930v4}

Submitted on 5 Jun 2008

HAL is a multi-disciplinary open access archive for the deposit and dissemination of scientific research documents, whether they are published or not. The documents may come from teaching and research institutions in France or abroad, or from public or private research centers.
L'archive ouverte pluridisciplinaire HAL, est destinée au dépôt et à la diffusion de documents scientifiques de niveau recherche, publiés ou non, émanant des établissements d'enseignement et de recherche français ou étrangers, des laboratoires publics ou privés. 


\title{
Mass nouns and plural logic*
}

\section{David Nicolas}

\begin{abstract}
A dilemma put forward by Schein (1993) and Rayo (2002) suggests that, in order to characterize the semantics of plurals, we should not use predicate logic, but plural logic, a formal language whose terms may refer to several things at once. We show that a similar dilemma applies to mass nouns. If we use predicate logic and sets when characterizing their semantics, we arrive at a Russellian paradox. And if we use predicate logic and mereological sums, the semantics turns out to be too weak. We then develop an account where mass nouns are treated as non-singular terms. This semantics is faithful to the intuition that, if there are eight pieces of silverware on a table, the speaker refers to eight things at once when he says: The silverware that is on the table comes from Italy. We show that this account provides a satisfactory semantics for a wide range of sentences.
\end{abstract}

Keywords: Mass nouns, Singular terms, Plurals, Plural logic, Mereology

Affiliation: Institut Jean Nicod (EHESS-ENS-CNRS)

Correspondence: ENS - 29 rue d'Ulm - 75005 Paris - France

Email: david.nicolas@m4x.org

\footnotetext{
* I dedicate this paper to the memory of John Macnamara, psychologist and philosopher. Through his spoken words and written work, John made me discover, a long time ago, the fascinating topic of mass nouns and count nouns. (See La Palme-Reyes et al. 1994, 1999 for some of his last, collaborative work on the subject.) For discussion, I would like to thank Nicholas Asher, Francis Corblin, Steven Davis, Paul Egré, Randall Holmes, Paul Hovda, Kathrin Koslicki, Øystein Linnebo, Alex Oliver, Charles Parsons, Agustín Rayo, Barry Schein, Philippe Schlenker, Roger Schwarzschild, Lucia Tovena, Gabriel Uzquiano, Peter van Inwagen, and Sebastian Watzl, as well audiences at SOPHA 2006, Jean Nicod Colloquium 2006, Formal Semantics in Moscow 3, $16^{\text {th }}$ Amsterdam Colloquium, and Journées de Sémantique et Modélisation 2008. Special thanks to Brendan Gillon for his comments and encouragements over the years, and to Denis Bonnay and two anonymous referees for their very detailed and useful criticisms.
} 


\section{Introduction}

A singular term of a natural language is a term that, each time it is used to refer within an utterance, refers to a single individual. Thus, both John and this cat are singular terms, as we can see in the following sentence, uttered in appropriate contexts:

(1) John fed this cat.

By contrast, there is intuitively no reason to think that John and Bill and these cats are singular terms. Each expression may refer to several things, and may thus be said to be a non-singular term:

(2) John and Bill fed these cats.

(Typically, a plural expression refers to more than one thing. However, it can also refer to one thing only, as in the following sentence:

(3) The morning star and the evening star are the same star. ${ }^{1}$ )

What about mass nouns, like wine and silverware? Consider the sentence:

(4) This wine costs a hundred euros.

If there is one bottle of wine in front of us, it seems that one thing is being referred to. However, if there are six bottles of wine, it seems, intuitively, that six things are being referred to. The goal of this paper is to see whether a formal account of the semantics of mass nouns can do justice to this intuition.

This is done in light of relatively recent works in logic and on plurals. A dilemma put forward by Schein $(1993,2006)$ and Rayo $(2002,2006)$ suggests that, in order to characterize the semantics of plurals, we should not use predicate logic, but plural logic, a formal language whose terms may refer to several things at once. What about mass nouns, then? Should plural logic be used to represent the truth-conditions of sentences in which mass nouns appear?

We explore several issues that are linked to this question. We first present the data that a semantics of mass nouns must account for (\$2). We explain how the dilemma arises for plurals (§3), and we show that it also applies to mass nouns $(\S 4)$. We then use plural logic to develop a semantics of mass nouns that treats them as non-singular terms, which may refer to several things at once ( $\$ 5$ ).

In one respect, the account we put forward may seem partly analogous with set-theoretic approaches, which would assign a set of things as the denotation of mass noun phrases. Indeed, the non-singular semantics we shall propose assigns some things (rather than a set of things) as the denotation of such phrases. Now, various kinds of sentences have been seen as presenting difficulties for settheoretic approaches (cf. Bunt (1985) and Pelletier \& Schubert (2003)). ${ }^{2}$ Chief among them are the following:

(5) The gold on the table weighs seven ounces.

(Bunt 1985)

(6) All phosphorus is either red or black.

(Roeper 1983)

\footnotetext{
${ }^{1}$ For recent discussions concerning what meaning should be attributed to the plural morpheme, see Sauerland et al. (2005) and Farkas \& de Swart (2007).

${ }^{2}$ Sentences like (6) are also problematic for mereological approaches to the semantics of mass nouns. Cf. Roeper (1983), and the Appendix (\$7) below, which contains a brief overview of former approaches to the semantics of mass nouns.
} 
(7) The clay that was on the desk on July $1^{\text {st }}$ is identical with the clay that was on the table on July $2^{\text {nd }}$.

Context of utterance: three solid bits of clay were on the desk on July $1^{\text {st }}$, and two solid bits of clay were on the table on July $2^{\text {nd }}$.

(Example inspired by Cartwright 1965.)

We show in $\$ 5$ that the non-singularist account we propose is able to deal with such sentences.

\section{Data that a semantics of mass nouns must account for 2.1. General observations}

In many languages like English, common nouns are divided into two morphosyntactic subclasses, mass nouns and count nouns (Krifka 1991, Gillon 1992). A defining characteristic of mass nouns, like milk, gold, and furniture, is that they are invariable in grammatical number, while count nouns, like rabbit, bottle, and table, can be used in the singular and in the plural. Depending on the language, this basic morphosyntactic difference between the two types of nouns is often supplemented by differences as to the determiners they can combine with. Thus, in English, mass nouns can be used with determiners like much and a lot of, but neither with one nor many. On the contrary, count nouns can be employed with numerals like one and determiners like many, but not with $m u c h .^{3}$

The invariability of mass nouns suggests that grammatical number has no semantic import with these nouns. Morphosyntactic differences between languages confirm this. In English and French, mass nouns are typically singular. According to Corbett $(2000, \S 5.8 .1)$, in Turkana and in Bantu languages, some mass nouns are singular and some are plural, while in Manam, all mass nouns are plural. Moreover, in English, mass nouns tolerate determiners that can also be used with plurals: all, any, some, the. Not so in French, where the determiner must be singular: tout or / *tous or (all / any gold), de l'or / *des or (some gold), l'or / *les or (the gold). And finally, mass expressions and plurals often seem to be coreferential (cf. Gillon 1992):

(8) The silverware is in the drawer.

(9) The pieces of silverware are in the drawer.

These data suggest that grammatical number has no semantic consequence for mass nouns. ${ }^{4}$

${ }^{3}$ It is of course well known that mass nouns can, in certain contexts, be used as count nouns

(i) You should take a hot milk with some honey

and vice versa

(ii) You will find a lot of rabbit around here.

One then talks of conversion; cf. Gillon (1992), Nicolas (2002a: chapters 1 and 7), and Nicolas (2002b). Conversion is a common grammatical possibility, whereby a member of a grammatical category is used in the morphosyntactic environment characteristic of another grammatical category. For instance, proper names can be used as common nouns:

(iii) The professor has two Picassos in his class.

${ }^{4}$ As Corbett (2000: 172) puts it, mass nouns are "simply off the scale of number-differentiality."

It follows from all this that the singular number of the terms it, this and something also lacks semantic import when these terms apply to what a mass noun applies to, as in the following sentences, where $M$ is a mass noun:

(i) This is M. 
A semantics for these nouns should specify the truth conditions of the sentences in which they appear. It should be able to do so for the various kinds of noun phrases that mass nouns can head: demonstrative and definite noun phrases (this $M$, the $M$ that $Q s$, e.g., the gold that is on the table), and quantified noun phrases (some / a lot of / all / any M, e.g., some gold). Doing so, the semantics should account for the various construals to which sentences containing mass nouns are liable: collective and non-collective construals (cf. Gillon 1992). We characterize these construals in the next section (\$2.2), in connection with each kind of noun phrase.

Similar construals are observed for sentences containing plurals. This tells us that the semantics of mass nouns and that of plurals must share some significant features, though they need not be identical. ${ }^{5}$ Let us indicate one of these properties here: mass nouns and plurals refer cumulatively (cf. Quine 1960 for mass nouns). Consider a mass noun $M$. Suppose that, in a given circumstance, we can truly say of something x that This is $M$ (with this referring to x) and of something distinct, $\mathrm{y}$, that This is $M$ (with this now referring to y). Then, in the same circumstance, we can refer to $\mathrm{x}$ and $\mathrm{y}$ together, and say of $\mathrm{x}$ and $\mathrm{y}$ that This is $M$. This characteristic of mass nouns is called cumulative reference. Plurals have the same property. Let $N s$ be a plural count noun. If these are Ns and those are Ns, then we can refer to these and those together, and say of all of them that they are Ns.

Sentences containing mass nouns, plurals and singular count nouns are also liable, in certain cases, to so-called generic construals:

(10) Gold is expensive.

(11) Dinosaurs are extinct.

(12) The potato is highly digestible.

Following Gillon (1990), we take these to correspond to a variety of independent phenomena, which are not specifically related to mass nouns and plurals. ${ }^{6}$ So we will have nothing to say about them in this paper.

Finally, let us discuss one property that various authors have ascribed to mass nouns, the property of having minimal parts. Let us say that an object $\mathrm{x}$ is a minimal part for a mass noun $M$ if $M$ applies to $\mathrm{x}$ (i.e., the sentence This is $M$ is true when the demonstrative this refers to x), but $M$ applies to no part of $\mathrm{x}$ (there is no part $\mathrm{y}$ of $\mathrm{x}$ such that the sentence That is $M$ is true when that refers to y). Formally, the fact that $\mathrm{x}$ is a minimal part for the noun $M$ may be rendered as follows, the notion of strict part being denoted by ' $<$ :

(13) $\quad \mathrm{M}-\min (\mathrm{x}) \equiv_{\text {def }} \mathrm{Mx} \wedge \neg \exists \mathrm{y}(\mathrm{My} \wedge \mathrm{y}<\mathrm{x})$

A mass noun like furniture has minimal parts: each piece of furniture is a minimal part for the noun. ${ }^{7}$ However, a mass noun like time is plausibly taken not to have

(ii) John bought some M yesterday. It is in the living room.

(iii) There is something in the living room. It is some $\mathrm{M}$.

${ }^{5}$ This is well known in the literature on the topic; see for instance Link (1983), Gillon (1992), Chierchia (1998), and Nicolas (2002: chapter 3).

${ }^{6}$ For reviews of the literature on generic construals, see Krifka et al. (1995) and Pelletier \& Asher (1997).

${ }^{7}$ It may be noted that mass nouns like furniture and silverware behave differently from count nouns like gaggle and fleet. Thus, one can talk of a gaggle of geese and a fleet of ships, but not of furniture of tables or silverware of knives. These mass nouns also differ from count nouns 
minimal parts: any time $\mathrm{x}$ has some time $\mathrm{y}$ as part. The same seems to be true of a mass noun like space. ${ }^{8}$ Consider now mass nouns that name substances, like water and gold. Modern physics suggests that they have minimal parts, namely their individual molecules. However, it is unclear whether the customary meaning of a word like water has changed because of the discoveries of modern science. Be that as it may, some mass nouns seem to have minimal parts (like furniture and silverware), while others do not (like time and space). We can conclude that grammar is mute on this score: the fact that a noun belongs to the class of mass nouns does not determine, by itself, whether the noun should have minimal parts or not (this is also the conclusion of Bunt (1985)). ${ }^{9}$

\subsection{Collective and non-collective construals}

According to Gillon (1992), a sentence containing a mass noun may receive collective and distributive construals, modulo the meaning of the particular lexical items composing the sentence, context of speech and knowledge of the world. ${ }^{10}$ While Gillon has given a few examples of these construals, we find that he has not considered the phenomena in enough detail. We therefore attempt to characterize the phenomena with more precision and accuracy. We first characterize the construals of sentences containing definite and demonstrative noun phrases. We then look at the construals of sentences containing quantified noun phrases.

Consider a sentence whose subject is a definite or demonstrative mass noun phrase:

(14) This silverware costs a hundred euros.

The sentence may be true if the silverware costs, altogether, a hundred euros: this is the collective construal of the sentence. It may be true if each piece of silverware, by itself, costs a hundred euros: this is the distributive construal. It

like shipment. Count nouns are characterized by the fact that they admit the singular / plural contrast. For instance, one can talk of one shipment, or of several shipments. This suggests that a shipment is more than a mere plurality of things. Some furniture, on the other hand, is just some pieces of furniture (a "mere plurality"). See Simons (1997) for various conceptual distinctions between different kinds of "collections".

${ }^{8}$ It is at least very much unclear whether these nouns have minimal parts. Therefore, the grammar that the linguist hypothesizes should not forbid a mass noun to be without minimal parts.

${ }^{9}$ A referee asked whether the distinction between mass nouns applying to substances (like water) and mass nouns applying to "collections" (like furniture) is reflected in the grammar. In the case of a mass noun applying to a "collection", there is a specific term that identifies what counts as a minimal part for the noun. Thus, one may talk of a piece of furniture, fifty heads of livestock, or seven grains of salt. This is not the case for mass nouns like water and gold, for which no minimal part is linguistically specified. Instead, they can be combined with various terms for purposes of measurement or individuation: a liter / glass / puddle of water, three bits / nuggets of gold. So there is a small lexical and grammatical difference between nouns of both kinds. (For more on this, see Krifka 1991.)

Given this, could the semantic rules for mass nouns denoting substances differ substantially from those for mass nouns denoting "collections"? By morphosyntactic criteria, terms of both kinds belong to the same subclass of common nouns, namely, to the class of mass nouns. The simplest hypothesis is therefore that the same general semantic rules apply to all mass nouns alike. Our account conforms to this hypothesis.

${ }^{10}$ Remark: Sentences containing plurals also receive such construals. This is well documented by Gillon $(1992,1996)$ and Schwarzschild (1996). This may be confirmed by replacing mass nouns by plurals in the examples we give below. 
may also be true if the silverware demonstrated consists in two sets of silverware, each set of silverware costing, by itself, a hundred euros: this may be called an intermediate construal.

A partly similar range of construals is observed with a mass noun like wine:

(15) This wine costs a hundred euros.

A collective construal would assert that the wine, altogether, costs a hundred euros. A non-collective construal may be obtained, for instance, when the wine demonstrated consists of two cases of wine. The speaker could then assert that each case of wine costs a hundred euros. What about a distributive construal of the sentence? In fact, as observed by a referee, this notion does not apply in this case, since a mass noun like wine has no linguistically specified minimal part.

Therefore, the distinction that concerns all mass nouns is not that between collective and distributive construals (nor that between collective, distributive and intermediate readings), but rather, that between collective and non-collective construals. What happens is that, in the specific case of mass nouns like silverware, one can identify, among the non-collective construals, one reading that may be called distributive and other readings that may be called intermediate.

A simple clause may receive collective and non-collective construals as long as at least one of the arguments of the verb is a mass expression (cf. Gillon 1996). The mass noun phrase may be the subject, the object, or the indirect object of the verb, or the object of a prepositional phrase complementing the verb. Take the sentence:

(16) Bill ran through the furniture.

Its most likely construal is a collective one: Bill ran among the pieces of furniture. Imagine, however, that the furniture consisted in several chairs that were two meters high. Then a non-collective construal becomes possible, whereby Bill literally ran through each piece of furniture. One could also imagine that the furniture is divided into groups, each group being arranged to form a kind of Arc of Triumph. This would also correspond to a non-collective construal.

This example shows that the specific meanings of the verbal expression and its arguments, combined with knowledge of the world and context of speech, may render a type of construal more, or less, plausible. We also see that noncollective, "intermediate" construals may be harder to get than the collective reading, or than the "distributive" reading if there is one. Such construals require specific information about the context in order to become available. They are often easier to get when the verb has several arguments, as in the following example due to Gillon (1992):

(17) This fruit was wrapped in that paper.

A non-collective, "intermediate" construal with respect to its first argument (this fruit) would be one where there are several pieces of paper, each enclosing several pieces of fruit.

In the examples we have given so far (as well as in those considered by Gillon), non-collective construals always correspond to partitions of the denotation of the mass noun phrase. It is well known that plurals can receive collective and non-collective construals. In their case, non-collective construals may correspond not only to partitions, but also, more generally, to 
coverings $^{11}$ (cf. Gillon 1992, Schwarzschild 1996). Imagine that any two of three men composed one opera together. This may make the following sentence true:

(18) These men wrote these operas.

The three pairs of men do not correspond to a partition of the three men, but to a covering. So can we find similar cases with mass nouns? This is harder than with plurals. Still, consider the sentence:

(19) These men stole that gold.

It may be that some gold was repeatedly part of the gold stolen by some of the men. The situation would correspond to a covering of the gold that is not a partition. Likewise, with

(20) This livestock carried that furniture

it may be that some pieces of furniture were repeatedly part of the furniture carried by some of the livestock. We conclude that the semantics of mass nouns should leave room, not only for partitions, but also for all kinds of coverings.

Let us now look at quantified mass noun phrases, starting with a lot of $M$ and some $M$. We examine what construals are available with each of these expressions (something that Gillon does not do in any detail). Consider first sentences with a lot of. The sentence

(21) Bill ran through a lot of furniture

asserts that there was a lot of furniture, and that Bill ran through it. It may receive a collective construal: Bill ran among many pieces of furniture. It may also receive a non-collective construal: Bill ran through each of many pieces of furniture. Moreover, a sentence like

(22) A lot of fruit was wrapped in a lot of paper

may receive a non-collective construal according to which there were many pieces of fruit and many pieces of paper, each piece of paper enclosing some pieces of fruit. $^{12}$

Consider now examples with some. In this case, the sentence

(23) Bill ran through some furniture

simply asserts that there was some furniture and that Bill ran through it.

Let us now look at quantified mass noun phrases of the form all $M$ or any $M$. Imagine a man who goes into a shop and looks carefully at what is sold. Later, he reports to his wife:

(24) All silverware costs a hundred euros.

${ }^{11}$ A notion of covering akin to that used by Gillon may be defined as follows.

(i) $\quad \mathrm{A}$ set $\mathrm{X}$ is a covering of a set $\mathrm{Y}$ just in case the mereological sum of the elements of $\mathrm{X}$ is identical with the mereological sum of the elements of $Y$.

(See $§ 4.2$ for a brief exposition of classical mereology.)

Remark: Gillon uses a more specific notion, that of aggregation. An aggregation is a covering no element of which is a mereological part of another element. We prefer to use the more general notion. Nothing of substance hinges on that choice.

${ }^{12}$ Just like a gradable adjective (like tall or wise), a lot of seems to invoke a contextually specified standard (or class of comparison). What counts as a lot of paper depends on the linguistic and metalinguistic context. The context may change from one utterance to another. This explains why the following piece of discourse seems to be coherent, as noted by a referee:

(i) Paper was scarce in those days. Still, that piece of fruit came wrapped in a lot of paper.

The contextually specified standard invoked by the adjective scarce in the first utterance is different from the standard invoked by $a$ lot of in the second utterance. 
A non-collective construal is available: each piece of silverware costs a hundred euros. Another non-collective construal also seems to be possible: what is sold consists in several sets of silverware and each set costs a hundred euros. With some stretch, one may perhaps imagine a collective reading, but it seems to be parasitic on the construal obtained with the phrase all the silverware:

(25) All the silverware costs a hundred euros.

So a collective construal with all silverware appears in fact to be infelicitous. Likewise, non-collective construals (but not collective readings) seem to be available with phrases of the form any $M$.

Having characterized the main data that a semantics of mass nouns must account for, we now turn to the dilemma that has been presented for a semantics of plurals based on predicate logic, before examining whether the dilemma applies to mass nouns as well.

\section{The dilemma for plurals}

\subsection{The dilemma}

The constants and variables of predicate logic are singular in the following sense. Under any interpretation, a constant is interpreted as one individual, and under any assignment, a variable is interpreted as one individual. Now, the representation of a plural expression like John and Bill in predicate logic is plausibly taken to be a constant. So it will be interpreted as an individual in the domain of interpretation. Starting with Bolzano and Frege, two kinds of proposals have been made for what this individual may be: it may be a set, like the set whose members are John and Bill, or a whole, like the mereological sum of John and Bill.

Recently however, several arguments have been put forward to show that characterizing the truth-conditions of sentences containing plurals with the help of predicate logic is unsatisfactory; cf. Schein $(1993,2006)$, Oliver \& Smiley (2001), Rayo (2002, 2006), Yi (2005), and McKay (2006). ${ }^{13}$ For lack of space, we present here only two of these arguments, under the form of a dilemma. The first argument is specifically directed against a representation of plurals in terms of sets, the second against a representation of plurals in terms of mereological sums.

On the one hand, if we use sets to characterize the semantics of plurals, we run into a contradiction similar to that discovered by Russell in naive set theory (cf. notably Boolos 1984 and Schein 1993). Consider indeed the following sentence schema, where $N$ is a count noun and $P$ is a distributive predicate:

(26) There are some Ns such that an $\mathrm{N}$ is one of them just in case it is not P / does not $\mathrm{P}$.

We get an intelligible and true instance of the schema if we replace $N$ by animal and $P$ by have a tail (given that some animals do not have a tail):

(27) There are some animals such that an animal is one of them just in case it does not have a tail.

Suppose that the truth-conditions of sentences containing plurals are specified using predicate logic and sets in a systematic and uniform manner. Then the representation of the sentence schema becomes:

(28) $\exists \mathrm{x}(\operatorname{set}(\mathrm{x}) \wedge \mathrm{x} \neq \varnothing \wedge \forall \mathrm{y}(\mathrm{Ny} \rightarrow(\mathrm{y} \in \mathrm{x} \leftrightarrow \neg \mathrm{Py})))$

\footnotetext{
${ }^{13}$ Of course, the problem is not with the syntax of predicate logic, but with how it is interpreted.
} 
For example:

(29) There is a non-empty ${ }^{14}$ set $\mathrm{x}$ such that, for any animal $\mathrm{y}, \mathrm{y}$ is a member of $\mathrm{x}$ just in case y does not have a tail.

So far, so good. Yet, replace $N$ by set and $P$ by a member of itself. This instance of the schema is still intelligible and true:

(30) There are some sets such that a set is one of them just in case it is not a member of itself.

But if we represent plurals using sets, we obtain something analogous to a Russellian contradiction:

(31) $\exists \mathrm{x}(\operatorname{set}(\mathrm{x}) \wedge \mathrm{x} \neq \varnothing \wedge \forall \mathrm{y}(\operatorname{set}(\mathrm{y}) \rightarrow(\mathrm{y} \in \mathrm{x} \leftrightarrow \mathrm{y} \notin \mathrm{y})))$

If we suppose that $x$ is a member of itself, we conclude that $x$ should not be a member of itself. And if we suppose that $\mathrm{x}$ is not a member of itself, we conclude that $x$ should be a member of itself. This indicates that (31) is false, contrary to the assumption that it captures the meaning of (30), which is true.

First remark: The argument presupposes that the domain of the existential quantifier ' $\exists \mathrm{x}$ ' is the same as that of the universal quantifier ' $\forall \mathrm{y}$ '. With Williamson (2003), we suppose that it is possible to quantify over everything there is. In particular, we suppose that, in the above English sentence, it is possible to quantify over all the sets there are. This ensures that the set $\mathrm{x}$ that is used in the representation of the sentence is among the sets that are mentioned in the sentence. Of course, in everyday talk, quantification is often contextually restricted. Thus, someone who says

(32) Each bottle is in the fridge

is presumably talking of each of some contextually relevant bottles, not of every bottle in the world. But it is not always so. Take the sentence

(33) Every human being is entitled to freedom.

This claim is understood as being about all human beings, not about only some of them. So it is naturally formalized as

(34) $\forall x$ (human-being( $x) \rightarrow$ entitled-to-freedom(x))

where the universal quantifier ranges over absolutely everything. (If the quantifier was restricted, then some human beings might be left out.) Likewise, consider claims like

(35) Everything is self-identical

and

(36) Nothing is abstract.

Someone making the first claim intends to be talking about absolutely everything there is, and probably thinks that, so understood, he is uttering a mere truism. Someone making the second claim is denying that there can be something abstract (i.e., that there can be abstract objects). His claim is naturally formalized along the lines of

(37) $\quad \forall \mathrm{x}(\neg \mathrm{abstract}(\mathrm{x}))$

where the universal quantifier ranges over absolutely everything. (If the quantifier was restricted, (37) would not capture what the speaker intends to express, for

\footnotetext{
${ }^{14}$ The precision that the set $\mathrm{x}$ is non-empty is necessary, since the original English sentence does assert the existence of some animals.
} 
some objects would be left out.) Such cases suggest that unrestricted quantification is genuinely possible. ${ }^{15}$

Second remark: As indicated above, we held that a satisfactory semantics for plurals should work in a systematic and uniform manner. In line of this, consider

(38) There is an animal that does not have a tail

and its natural representation

(39) $\exists \mathrm{x}(\operatorname{animal}(\mathrm{x}) \wedge \neg$ have-a-tail(x))

(27) and (38) are true in the same circumstances. Yet, (39) would be an inappropriate representation of (27), since it would fail to translate various meaningful components of (27). In particular, (27) contains as a component the expression is one of. So its meaning must get represented in an appropriate translation of (27). The expression is one of takes a singular noun phrase as first argument and a plural noun phrase as second argument (This cat is one of our animals, John is one of them, etc). It is collective on its second argument: when John is one of them, he is one of them taken together; he is not, say, one of him and one of her. So an adequate set-theoretic representation of

(40) John is one of them

will have to be something like

(41) $\mathrm{j} \in \mathrm{x}$

where $\mathrm{x}$ is the set of things that are referred to. The same is true for a faithful representation of (27), which will have to be along the lines of (29). And so paradox will arise when trying to represent (30). ${ }^{16}$

On the other hand, if we use mereological sums (but not sets), the semantics turns out to be too weak. Indeed, there exist count nouns $M$ and $N$ such that an $\mathrm{M}$ is not an $\mathrm{N}$, but the Ms and the Ns have the same mereological sum. Then, for any given predicate $P$, the semantics attributes the same truth-value to the sentences The Ms $P$ and The Ns $P$. With certain predicates, however, these sentences have, intuitively, opposite truth-values.

Here, let us consider just one example given by Rayo (2002). Suppose that there are several piles of grains, which are scattered, i.e., spatially separated from one another in irregular fashion. Then the sum of the piles of grains is identical with the sum of the grains. But the sentence

(42) The piles of grains are scattered

is true, while

\footnotetext{
${ }^{15}$ See Williamson (2003) for extensive discussion and other arguments in favor of unrestricted quantification. For opposition, see for instance Glanzberg (2004). For more recent discussion, see the chapters in Rayo \& Uzquiano (2006a).

${ }^{16}$ Likewise, consider the following sentence understood collectively:

(i) The animals that did not have a tail met on the hill.

The predicate met on the hill is true of the animals that did not have tail taken together. So to represent its meaning in predicate logic, we need a singularizing device. Hence, we might propose that the sentence is true just in case the set of animals that did not have a tail met_on_the_hill (where 'met_on_the_hill' is a translation of met on the hill in the metalanguage). But doing so, of course, we would run into a problem when considering:

(ii) The sets that do not belong to themselves are numerous.

The corresponding translation cannot work, since there can be no set of the sets that do not belong to themselves.
} 
The grains are scattered

seems to be false. (We do not consider an alternative understanding of the sentence, where each of the piles has been scattered and destroyed in the process, only grains remaining.)

It is possible to resist this dilemma. Concerning the first horn of the dilemma, several researchers defend notably an open-ended conception of sets, whereby it is impossible to refer to all sets at once (see Glanzberg 2004, and some works cited by Rayo \& Uzquiano 2006b). The second horn of the dilemma is likely to be resisted, for instance, by someone who admits the thesis of composition as identity. This thesis may be expressed as follows (cf. van Inwagen 1994). Let the ds be any things. Suppose that they have a mereological sum $t$, so that we may say that the ds compose $t$. Then they are identical to their mereological sum. ${ }^{17}$ Suppose that composition as identity is true. By transitivity of the identity relation, if some Ms have the same sum as some Ns, then the Ms and the Ns are identical. Therefore, any impression that The $M s P$ is true while The Ns $P$ is false must be either mistaken (it should not really be trusted), or else explainable using well-known independent facts-for instance, perhaps the predicate $P$ creates an intensional context, and the expressions the $M s$ and the Ns induce different modes of presentation of the same things. ${ }^{18}$

In this work, however, we take the dilemma to be sound, as well as other arguments against a representation of the truth-conditions of sentences containing plurals in predicate logic. In particular, together with Williamson (2003), we think that absolutely unrestricted quantification is genuinely possible, hence it is possible to refer to all sets. And together with van Inwagen (1994) and Yi (1999), we reject the thesis of composition as identity (see also note 25). So plurals should not be represented in predicate logic. An attractive alternative is offered by plural logic (see Rayo 2002, 2006, Oliver \& Smiley 2006, Yi 2005, 2006, McKay 2006, Linnebo 2008, and Linnebo \& Nicolas 2008). ${ }^{19}$ Plural logic possesses plural constants and variables, which may be interpreted as one or several individuals of the domain of interpretation. This makes for a natural representation of the semantics of plurals.

\subsection{Plural logic}

We give here a brief sketch of one particular instance of plural logic, referring the reader to the authors above for detailed exposition and variations. As we said, predicate logic has constants and variables that are singular. Under any interpretation and variable assignment, a term (be it a constant or a variable)

\footnotetext{
${ }^{17}$ Remark: The thesis is sometimes expressed using a narrower notion of composition, notably by van Inwagen (1990) himself. In Material beings, van Inwagen states that the ds compose t just in case no two ds overlap and $t$ is the mereological sum of the ds. This terminological difference is not important.

${ }^{18}$ Alternatively, one may want to reject the assumption that the parthood relation is extensional, namely, that if $\mathrm{x}$ and $\mathrm{y}$ have the same mereological parts, then they are identical. One would then also reject the thesis of composition as identity, since it seems to imply that the parthood relation must be extensional. However, this would only be a first step in denying the second horn of the dilemma, as the friends of plural logic have other arguments against the use of mereological sums to characterize the semantics of plurals (cf. notably Oliver \& Smiley 2001, Yi 2005, and McKay 2006).

${ }^{19}$ Simons (1982) and Boolos (1984) were early advocators of plural logic.
} 
is interpreted as one individual of the domain of interpretation. A formula consisting of a predicate whose argument is a constant is true just in case the constant is interpreted as one individual that satisfies the property expressed by the predicate.

Plural logic possesses singular and plural constants and variables. Under any interpretation and variable assignment, a plural term (a constant or a variable) may be interpreted as one or more individuals of the domain of interpretation. A formula consisting of a predicate whose argument is a plural constant is true just in case the constant is interpreted as one or more individuals that jointly satisfy the predicate. By convention, variables like ' $x$ ', ' $y$ ' and ' $z$ ' are singular variables, while variables ending with an 's', like 'xs', ' $y s$ ' and ' $z s$ ', are plural. Quantifiers apply both to singular and plural variables. ' $\exists \mathrm{x}(\mathrm{Px})$ ' may be read 'there is some thing that Ps' if the predicate corresponds to a verb, and 'there is some thing that is (a) P' if the predicate corresponds to a common noun. ' $\exists$ xs (Pxs)' may be read 'there are some things (one or more) that jointly $\mathrm{P}$ ' if the predicate corresponds to a verb, and 'there are some things (one or more) that are $\mathrm{P}$ ' if it corresponds to a common noun. A predicate may have one or more argument places, and in each argument place, it may accept singular terms, plural terms, or both.

The predicate among plays a special role in plural logic, where it is treated as a logical predicate, together with identity. We note it ' $\angle$ '. ' $\mathrm{xs} \angle \mathrm{ys}$ ' may be read 'the xs are among the ys' (they are some of the ys); ' $\mathrm{x} \angle \mathrm{ys}$ ' may be read ' $\mathrm{x}$ is among the ys' (it is one of the ys). This equivalence holds:

(44) ys $\angle \mathrm{zs} \leftrightarrow \forall \mathrm{x}(\mathrm{x} \angle \mathrm{ys} \rightarrow \mathrm{x} \angle \mathrm{zs})$

Some things ys are among some things zs just in case any thing $\mathrm{x}$ that is among the ys is also among the zs.

(Nota bene: Here and in what follows, we drop initial universal quantifiers to enhance readability. Thus, in (44), the initial quantifiers ' $\forall \mathrm{ys}$ ' and ' $\forall \mathrm{zs}$ ' have been dropped.)

And the following are axiom schemata of plural logic:

$\exists \mathrm{x}(\mathrm{Qx}) \rightarrow \exists \mathrm{zs}(\forall \mathrm{y}(\mathrm{y} \angle \mathrm{zs} \leftrightarrow \mathrm{Qy})) \quad$ Plural comprehension

If some thing $x$ Qs, then there are some things, the $z s$, such that some thing $\mathrm{y}$ Qs just in case it is among them.

$\forall \mathrm{x}(\mathrm{x} \angle \mathrm{ys} \leftrightarrow \mathrm{x} \angle \mathrm{zs}) \rightarrow$ (Qys $\leftrightarrow$ Qzs) $\quad$ Plural indiscernibility

For any things ys and any things zs, if they have the same things among them, then they satisfy the same formulas.

The theory of truth and the model theory of plural logic differ from those employed for predicate logic. The metalanguage in which such theories are expressed possesses terms that can refer to several things at once, and predicates that can be satisfied collectively by several things. For predicate logic, a model is specified using sets. In particular, a set fixes the universe of discourse (what objects the quantifiers range over), and a subset of this set specifies the interpretation of a one-place predicate. For plural logic, the model theory does without sets, in order to avoid set-theoretic paradoxes like the paradox mentioned in the last section. The universe of discourse is not fixed by a set of things, but by these things themselves. They may be referred to using a plural constant in the metalanguage.

What about predicates? How can their interpretation be specified? McKay (2006) and Yi (2006) use worldly properties and relations in order to 
interpret predicates (see also Oliver \& Smiley 2006). A formula like 'Pj' is true if and only if the object that interprets the constant ' $\mathrm{j}$ ' has the property that interprets the predicate ' $\mathrm{P}$ '. Doing so has the following limitation. The metalanguage refers to properties and relations. The object language, however, cannot refer to all the properties and relations that there are, for this would generate a Russellian paradox. Therefore, it does not seem possible, in the object language, to refer to and quantify over absolutely everything there is.

As indicated previously, with Rayo (2002, 2006) and Williamson (2003), we held that absolutely unrestricted quantification is genuinely possible. Therefore, we do not follow McKay and Yi. Rayo (2006) develops an alternative that allows for absolutely unrestricted quantification. It consists in using languages that contain not only plural terms, but also terms that are "superplural", "super-superplural", etc. A plural term may refer to several things. Therefore, we may say, in a slightly misleading way, that it may refer to a "plurality" of things. (This is misleading since the expression "a plurality" suggests that one thing is referred to, while a plural term simply refers to several things.) A superplural term may refer to several "pluralities". ${ }^{20}$ We may then say that certain things are among several "pluralities". This corresponds to a new logical primitive, which we note ' $\angle$ ', Thus, 'xs $\angle$ "zss' says that the xs are among several "pluralities", the zss. Superplural terms allow one to formulate a principle of superplural comprehension:

(47) $\exists$ xs (Qxs) $\rightarrow \exists$ zss $\left(\forall\right.$ ys (Qys $\leftrightarrow$ ys $\angle^{*}$ zss)) $\quad$ Superplural comprehension

If some things Q, then there are some "pluralities" (the zss) such that some things Q just in case they are among these "pluralities".

Thus, given a predicate, we can use a superplural term to refer to the "pluralities" that the predicate applies to. Rayo (2006) establishes a series of results concerning the model theories of various languages. In particular, the model theory of a language that contains singular and plural terms and allows for absolutely unrestricted quantification cannot be expressed in a language of the same type, but it can be expressed in a language that also contains superplural terms. As we will show, in order to specify the truth-conditions of sentences containing mass nouns and plurals, we will need to be able to refer to several "pluralities". We will do so using superplural terms.

\section{Does the dilemma found with plurals apply to mass nouns?}

We now want to examine the situation in the case of mass nouns. We consider two questions in turn.

\subsection{Do we run into a Russellian contradiction if the semantics of mass nouns is based upon sets and predicate logic?}

Suppose that we have a semantics of mass nouns based upon sets and predicate logic. Do we thereby run into a Russellian contradiction, as we did with plurals? Let us take a mass expression $M$ and consider the following sentence schema:

(48) There is some $M$ such that any $M$ that does not $P$ is part of it and no $M$ that Ps is part of it.

\footnotetext{
${ }^{20}$ Likewise, a "super-superplural" term would refer to several "pluralities of pluralities".
} 
Replacing $M$ by silverware and $P$ by the predicate have a blade, we get:

(49) There is some silverware such that any silverware that does not have a blade is part of it and no silverware that has a blade is part of it.

The predicates have a blade and not have a blade are distributive: they directly apply only to minimal parts of silverware (i.e., pieces of silverware). Therefore, the interpretation of the sentence may be paraphrased as:

(50) There is some silverware such that a minimal part of silverware (a piece of silverware) is part of it just in case it does not have a blade.

Assuming that there is some silverware that does not have a blade (e.g., a spoon), the sentence is both intelligible and true. To give its truth-conditions, recall the characterization of the notion of minimal part for a mass noun $M$ given in $\S 2.1$

(51) $\quad \mathrm{M}-\min (\mathrm{y}) \equiv_{\text {def }} \mathrm{My} \wedge \neg \exists \mathrm{z}(\mathrm{Mz} \wedge \mathrm{z}<\mathrm{y})$

Using sets and predicate logic, the sentence may then be represented as follows:

(52) $\exists \mathrm{x}(\operatorname{set}(\mathrm{x}) \wedge \mathrm{x} \neq \varnothing \wedge \forall \mathrm{y}($ silverware-min$(\mathrm{y}) \rightarrow(\mathrm{y} \in \mathrm{x} \leftrightarrow \neg$ has-a-blade(y)))

Or in other words:

(53) $\exists \mathrm{x}(\operatorname{set}(\mathrm{x}) \wedge \mathrm{x} \neq \varnothing \wedge \forall \mathrm{y}$ (piece-of-silverware(y) $\rightarrow(\mathrm{y} \in \mathrm{x} \leftrightarrow \neg$ has-ablade(y))))

Using this sentence schema, can we get a contradiction? Let us try with a hypothetical mass noun, setware, which denotes sets. This mass noun functions just like the mass nouns livestock and silverware. Some livestock, we may say, is one or more animals of the farm. Likewise, some setware, we may say, is one or more sets. Replacing $M$ by setware and $P$ by the distributive predicate $b e a$ member of itself in our sentence schema, we get:

(54) There is some setware such that any setware that is not a member of itself is part of it and no setware that is a member of itself is part of it. ${ }^{21}$

The sentence is understandable. Its interpretation may be paraphrased as:

(55) There is some setware such that a minimal part of setware (a set) is part of it just in case it not a member of itself.

Assuming that there is some set that is not a member of itself, the sentence is true. It may be represented as:

(56) $\exists \mathrm{x}(\operatorname{set}(\mathrm{x}) \wedge \mathrm{x} \neq \varnothing \wedge \forall \mathrm{y}(\operatorname{setware}-\min (\mathrm{y}) \rightarrow(\mathrm{y} \in \mathrm{x} \leftrightarrow \mathrm{y} \notin \mathrm{y})))$

Or in other words:

(57) $\exists \mathrm{x}(\operatorname{set}(\mathrm{x}) \wedge \mathrm{x} \neq \varnothing \wedge \forall \mathrm{y}(\operatorname{set}(\mathrm{y}) \rightarrow(\mathrm{y} \in \mathrm{x} \leftrightarrow \mathrm{y} \notin \mathrm{y})))$

So, using the mass noun setware, we fall into the same kind of Russellian contradiction as we did with plurals. ${ }^{22}$ Of course, this mass noun is a hypothetical one. Although this lessens the intuitive force of the argument, we think that the argument goes through just as well. As speakers of English, we have a clear, intuitive grasp of how mass nouns like livestock and silverware function. We also understand the count noun set in its mathematical usage and the plural expressions of which it is part (some sets, the sets, ...). So there is nothing that stands on the way of employing a new mass noun on the model of nouns like silverware, as a noun that can apply to any one or more sets. The mass noun setware is thus a possible and legitimate addition to English, though one that is not yet realized.

${ }^{21}$ Other sentences could be considered, for instance:

(i) Some setware is made of all and only non-self-membered sets.

${ }^{22}$ If we suppose that $\mathrm{x}$ is a member of itself, we conclude that $\mathrm{x}$ should not be a member of itself. And if we suppose that $\mathrm{x}$ is not a member of itself, we conclude that $\mathrm{x}$ should be a member of itself. So (57) is false, while it was meant to represent the meaning of (54), which is taken to be true. 
Let us add the following, independent consideration. Suppose that the semantics of mass nouns was based only upon sets. The overall semantics of English would become heterogeneous and thus extremely awkward, if not contradictory, when representing sentences that are understood collectively. Imagine indeed that there are two pieces of furniture, $a$ and $b$, and that the sentence

(58) This furniture weighs two hundred kilos

is understood as saying that the whole furniture together weighs this much. The semantics must attribute the property to weigh two hundred kilos to the set $\{a, b\}$, rather than to its members: part of the representation of the sentence will be 'Pc', where the singular constant ' $C$ ' is interpreted as the set $\{\mathrm{a}, \mathrm{b}\}$, and the predicate ' $\mathrm{P}$ ' corresponds to weigh two hundred kilos. Now, this would make it very difficult to integrate the semantics of mass nouns with that of plurals. Plurals, we have seen, should be represented using plural logic. Consider the sentence

(59) These pieces of furniture weigh two hundred kilos

understood collectively, its subject referring to a and b. Part of its representation will say that the predicate ' $\mathrm{P}$ ' applies jointly to some things denoted by a plural constant, 'cs': 'Pcs'. We would therefore have a predicate 'P' that applies both to singular terms interpreted as sets in the case of mass nouns, and to plural terms interpreted as ordinary things in the case of plurals. This would be extremely awkward, if not leading to contradiction.

\subsection{Can a semantics of mass nouns be based upon mereological sums and predicate logic?}

Let us now look at our second question: can a semantics of mass nouns be based upon mereological sums and predicate logic? The first thing is to be clear on the relevant mereological notions. They may be characterized as follows (cf. Simons 1987, Varzi 2006). From the notion of mereological part $(\leq)$ taken as primitive, the notions of proper part $(<)$, overlap $(\mathrm{O})$ and sum $(\sigma)$ are defined in this way:

(60) $\mathrm{x}<\mathrm{y} \equiv_{\text {def }} \mathrm{x} \leq \mathrm{y} \wedge \neg(\mathrm{x}=\mathrm{y})$

Proper part

(61) Oxy $\equiv_{\text {def }} \exists \mathrm{z}(\mathrm{z} \leq \mathrm{x} \wedge \mathrm{z} \leq \mathrm{y})$

Overlap

$\mathrm{x}$ and $\mathrm{y}$ overlap if they have a part in common

$\mathrm{z}=\sigma(\mathrm{x} / \mathrm{Rx}) \equiv_{\text {def }} \forall \mathrm{v}(\mathrm{Ovz} \leftrightarrow \exists \mathrm{y}(\mathrm{Ovy} \wedge \mathrm{Ry}))$ Sum of anything that Rs

$\mathrm{z}$ is the sum of anything that Rs if something overlaps $\mathrm{z}$ just in case it overlaps something that Rs

The axioms of classical mereology are then the following four axioms, plus an axiom schema for any formula ' $R$ ':

(63) $\quad x \leq x$

(64) $\mathrm{x} \leq \mathrm{y} \wedge \mathrm{y} \leq \mathrm{x} \rightarrow \mathrm{x}=\mathrm{y}$

Reflexivity

(65) $\mathrm{x} \leq \mathrm{y} \wedge \mathrm{y} \leq \mathrm{z} \rightarrow \mathrm{x} \leq \mathrm{z}$

Antisymmetry

(66) $\neg(\mathrm{y} \leq \mathrm{x}) \rightarrow \exists \mathrm{z}(\mathrm{z} \leq \mathrm{y} \wedge \neg \mathrm{Ozx})$

(67) $\quad \exists y(R y) \rightarrow \exists z(z=\sigma(x / R x))$

Transitivity

Strong supplementation

Existence of the sum

Mereology may be used in various ways in connection with the semantics of mass nouns. One possibility (which can be traced to Quine (1960)) consists in translating a sentence like This is wine as ' $\mathrm{c}=\mathrm{W}$ ', where ' $\mathrm{c}$ ' denotes what is demonstrated, ' $=$ denotes the relation of mereological part, and ' $W$ ' denotes the 
mereological sum of all the wine that there is. The problem with this is that there are some parts of wine (e.g., atoms) that do not count as wine, a problem which is even clearer in the case of mass nouns like furniture: the leg of a chair is not furniture. Therefore, we will not consider this possibility any further.

The question we are asking is the following. Can we devise a satisfactory semantics of mass nouns if we use predicate logic and identify the denotation of a mass noun phrase with a certain mereological sum? The idea would be that mass nouns function as singular terms: a definite mass noun phrase would always refer to one thing, a certain mereological sum. Imagine that there are thousands of bottles of wine in the cellar. Then the mass noun phrase the wine that is in the cellar would refer to an object $t$, the mereological sum of any wine that is in the cellar. Something similar would hold for any expression of the form the $M$ that $Q s$, where $M$ is a mass noun and $Q s$ is a verbal expression.

The first thing we should ask ourselves is whether the Russellian paradox found when using sets also arises when using mereological sums. Let us start with the sentence with the word silverware:

(68) There is some silverware such that any silverware that does not have a blade is part of it and no silverware that has a blade is part of it.

The sentence may be represented as:

(69) $\exists \mathrm{x}($ silverware $(\mathrm{x}) \wedge \forall \mathrm{y}($ silverware-min $(\mathrm{y}) \rightarrow(\neg$ has-a-blade $(\mathrm{y}) \leftrightarrow \mathrm{y} \leq \mathrm{x})))$

Or in other words:

(70) $\exists \mathrm{x}$ (silverware(x) $\wedge \forall \mathrm{y}$ (piece-of-silverware(y) $\rightarrow$ ( $\neg$ has-a-blade(y) $\leftrightarrow$ $\mathrm{y} \leq \mathrm{x}))$ )

Let us now see what happens for the sentence with the word setware and the distributive predicate be a member of itself:

(71) There is some setware such that any setware that is not a member of itself is part of it and no setware that is a member of itself is part of it.

Its truth-conditions are represented as:

(72) $\exists \mathrm{x}(\operatorname{setware}(\mathrm{x}) \wedge \forall \mathrm{y}($ setware-min $(\mathrm{y}) \rightarrow(\neg$ member-of-itself(y) $\leftrightarrow \mathrm{y} \leq \mathrm{x})))$ And so as:

(73) $\exists \mathrm{x}(\operatorname{setware}(\mathrm{x}) \wedge \forall \mathrm{y}(\operatorname{set}(\mathrm{y}) \rightarrow(\neg$ member-of-itself(y) $\leftrightarrow \mathrm{y} \leq \mathrm{x})))$

No contradiction necessarily arises from these truth-conditions. ${ }^{23}$

The second question we need to examine is whether we can identify the same kind of semantic weakness as the one observed with plurals. For such a weakness to be present, there would have to be two mass nouns, $M$ and $N$, such that some $\mathrm{M}$ is not (always) some $\mathrm{N}$, but the $\mathrm{M}$ and the $\mathrm{N}$ have the same mereological sum. Then, for any given predicate $P$, the semantics would attribute the same truth-value to the sentences The MPs and The N Ps. However, there might be predicates with which these sentences have, intuitively, opposite truthvalues.

\footnotetext{
${ }^{23}$ Uzquiano (2006) shows that various assumptions concerning set theory, mereology and plural logic lead to paradox. But this is not relevant here, where we are only considering set theory and mereology. (Moreover, there are various ways to escape the contradiction pointed out by Uzquiano, which he discusses. One of those, proposed by Lewis (1991), consists in adopting a set theory with proper classes, where a proper class cannot be a member of a set. This might have a cost concerning the foundations of mathematics, as Uzquiano thinks, but at least this position is consistent.)
} 
Let us consider an example due to Parsons (1970). Suppose that all wood is used to make up furniture and all furniture is made of wood. Then wood and furniture have the same parts, and so the mereological sum of the wood is identical with the mereological sum of the furniture. Therefore, all sentences of the form The wood Ps and The furniture Ps are predicted to have the same truthvalue. Yet, it might well be that

(74) The furniture is heterogeneous

is true, intuitively, while

(75) The wood is heterogeneous

is false.

One might object that the furniture and the wood that make it up are in fact distinct: if the furniture is broken, it ceases to exist, while the wood does not. This line of response, however, is not available once classical mereology has been adopted. For the first four axioms of classical mereology make it extensional: any two objects that have the same parts must be identical. Therefore, any semantics of mass nouns that makes crucial use of mereological notions should reject the assumption of extensionality. But this is not what is usually done, classical mereology being presupposed. Indeed, extensionality is necessary to ensure that the mereological sum of anything that Rs is unique. Without it, distinct things could well each be a mereological sum of anything that Rs. That would be problematic for assigning a unique semantic value to a simple mass noun phrase like the wood.

There is a different respect in which a semantics of mass nouns based upon mereological sums and predicate logic would be too weak. We saw in $§ 2.2$ that sentences containing mass nouns are liable to collective and non-collective construals. This was the case for the sentence

(76) This silverware costs a hundred euros.

The sentence may be true if the silverware costs, altogether, a hundred euros: this is the collective construal of the sentence. It may also be true if the silverware demonstrated consists in two sets of silverware, each set of silverware costing, by itself, a hundred euros: this is a non-collective construal. To capture noncollective construals, a notion of covering of the denotation of a mass noun phrase akin to that used by Gillon (1992) is needed, and to express this notion, the apparatus of sets, or something as expressive, is required. The notion may be characterized as follows.

(77) A set $\mathrm{X}$ is a covering of a set $\mathrm{Y}$ just in case the mereological sum of the elements of $\mathrm{X}$ is identical with the mereological sum of the elements of $\mathrm{Y}^{24}$

This definition uses both the notion of set and the notion of mereological sum. What is important here is that a covering is a set of things (which satisfies certain additional conditions). Using mereology and predicate logic alone, we could not refer to such a set. The notion of set, or something as expressive, like plural quantification in plural logic, is needed. The present definition uses mereological sums, but, as we will see in $\S 5.1$ another characterization that does not use them can be adopted in a non-singularist account.

\footnotetext{
${ }^{24}$ Remark: Gillon uses a slightly more specific notion, that of aggregation. See note 11
} 
We conclude from what precedes that a semantics of mass nouns based on mereological sums and predicate logic would be too weak. ${ }^{25}$ Before that, we had seen that a semantics formulated in predicate logic and based upon sets would lead to a Russellian contradiction. Thus, we face a similar dilemma with mass nouns as we did with plurals. This suggests adopting plural logic as a common framework for characterizing the semantics of mass nouns and that of plurals. This is what we do in what follows, where we use plural logic to develop a semantics of mass nouns that treats them as non-singular terms: terms that may refer to several things at once.

\section{A non-singular semantics for mass nouns}

We first specify a semantics that ignores tense, as well as other forms of intensionality. As remarked by Bunt $(1985: 6,22)$, the problems they pose are often not specific to mass nouns. Then, in $\S 5.2$, we show how tense can be added, in order to deal with statements of identity over time, which are relevant for mass nouns.

\subsection{The truth-conditions of various types of sentences}

Our account is inspired by the semantics proposed by Gillon (1992) for plurals and mass nouns. ${ }^{26}$ Formally, Gillon's account is singularist: a definite noun phrase is taken to be a singular term, which refers to a single object, a certain mereological sum. His key idea is that the interpretation of a sentence

\footnotetext{
${ }^{25}$ Moreover, we find the notion of unrestricted mereological sum cognitively and ontologically extravagant. Given any number of things, why should there exist in addition another object, their hypothetical mereological sum? Mereologists have tried to answer this charge in various ways. Lewis (1991) is famous for claiming the following. Whenever there are some things, the ds, they have a mereological sum, $t$, which the ds can be said to compose. This may be called the thesis of unrestricted composition. However, says Lewis, this does not increase our ontological commitments, since the ds are identical with their sum. The latter claim is known as the thesis of composition as identity. Lewis oscillates between two versions of the thesis, a strong one, and a weak one. The strong version says that the ds are literally identical with their mereological sum. The weak version says that the ds are so to speak identical with their mereological sum. In other words, composition resembles identity in several respects. Lewis finally acknowledges that the strong thesis - the claim that the ds are literally identical with their sum t-does not make sense, for two reasons. First, he knows of "no way to generalize the definition of ordinary one-one identity in terms of plural quantification". Second, "we do not really have a generalized principle of indiscernibility of identicals" (Lewis 1991: 87). So the strong version of the thesis of composition as identity should be rejected. What about the weak one? Lewis lists a number of analogies between composition and identity. However, why should analogies tell us anything concerning the ontological commitments of a theory that accepts a principle asserting the existence of unrestricted mereological sums? Formally, the theory asserts the existence of something (the mereological sum) that is distinct from any of the things it is the sum of (when it is the sum of two things or more). With van Inwagen (1994) and Yi (1999), we find this formal commitment substantive. Considerations of ontological economy therefore militate against the postulation of unrestricted mereological sums. Moreover, we see no reason why our ontology should contain objects that are so counter-intuitive. Varzi $(2000,2006)$ claims that psychological considerations of this sort should have no bearing on ontological issues. We disagree. Of course, a scientific understanding of the world and a common sense one may differ. Still, the intuitions of common sense should be explained and, given the choice between two theories that model equally well a certain range of data, priority should be given to the one that fits common sense intuition better.

${ }^{26}$ Schwarzschild (1996) proposes a similar account for plurals, and Chierchia (1998) is also greatly inspired by the work of Gillon.
} 
where a mass noun appears is relative to the choice of a covering of the denotation of the mass noun or of the mass noun phrase. We modify Gillon's notion of covering in order to arrive at a semantics that treats mass nouns as non-singular terms, which may refer to several things at once.

We take a mass noun to satisfy the following principle:
Mxs $\leftrightarrow \forall \mathrm{y}(\mathrm{y} \angle \mathrm{xs} \leftrightarrow \mathrm{My})$
Distributed reference
Some things are $\mathrm{M}$ just in case each of them is $\mathrm{M}$.

In this bi-conditional, the implication from the right to the left guarantees that a mass noun has the property of cumulative reference mentioned in $\S 2.1$ (if each of some things is $\mathrm{M}$, then these things referred to collectively are also $\mathrm{M}$ ).

This allows us to define a simple notion of denotation (or extension). In any circumstance in which a mass noun is used, we associate to it some things, the ds, which are its denotation:

(79) $\quad \operatorname{DEN}(M, \mathrm{ds}) \leftrightarrow \forall \mathrm{y}(\mathrm{My} \leftrightarrow \mathrm{y} \angle \mathrm{ds})$

The first argument of the two-place predicate 'DEN' is a linguistic expression, here a mass noun $M$. Its second argument is a term of plural logic. ' $\operatorname{DEN}(M, d s)^{\prime}$ ' can be read as ' $M$ denotes the $d s$ '.

By and large, we take the denotation of a mass noun $M$ to be objectively fixed: the ds comprise any thing that can be truly said to be $\mathrm{M}$ in the circumstance. To illustrate, consider the mass noun wine. We take it that, given the meaning of the noun, given how human cognition functions, and given the way the world is, there is an objective fact of the matter concerning what counts as wine. The greatest portion of wine in a bottle counts as wine, and so do many parts of this portion of wine. ${ }^{27}$ Perhaps there are minimal parts of wine that human beings can refer to. Or perhaps not. But in any case, what counts as wine is objectively fixed: it does not vary systematically with the way speakers may conceptualize what is in front of them. (Of course, in a given circumstance, the discourse may focus on only part of all the $M$ that there is. This is what happens when one says that the wine is in the fridge, since there is more wine in the world than in the fridge. The same is true with count nouns, since there are more than one fridge in the world. It is in this precise sense that the denotation of a common noun (mass or count) may vary with the circumstance in which it is used. This phenomenon is often called domain restriction.)

The denotation of a definite mass noun phrase of the form the $M$ that $Q s$ is then specified as follows:

(80) $\quad \mathrm{DEN}($ the $M$ that $\mathrm{Qs}$, as $) \leftrightarrow \forall \mathrm{v}(\mathrm{v} \angle \mathrm{as} \leftrightarrow \exists \mathrm{zs}(\mathrm{v} \angle \mathrm{zs} \wedge \mathrm{Mzs} \wedge$ Qzs) $)$

The denotation of the expression the $M$ that $Q s$ thus comprises any things zs that are some $\mathrm{M}$ that Qs. ${ }^{28}$ Given the axiom schema of superplural comprehension

\footnotetext{
${ }^{27}$ Remark: This provides a pragmatic explanation for why mass nouns designating substances cannot be combined with numerals (unless they are used as if they were count nouns, thereby receiving a different interpretation). Instances of a given substance overlap in a myriad of ways, so a count of the instances present in a given circumstance cannot be carried out. Of course, this is not true of mass nouns like furniture and silverware. So in their case, the limitation is purely syntactic.

${ }^{28}$ We assign the same denotation to the incomplete mass noun phrase $M$ that $Q s$. The theory could have assigned a "superplurality" as the denotation of definite and incomplete mass noun phrases, namely, the "superplurality" containing all the "pluralities" such that Mzs $\wedge$ Qzs. But then, a definite noun phrase and a demonstrative noun phrase would be assigned a formally different type of denotation, the former a "superplurality", and the latter an ordinary "plurality" (the things the
} 
stated in $\S 3.2$, the expression is guaranteed to have a (non-empty) denotation as soon as there are some things that are some $\mathrm{M}$ that Qs. ${ }^{29}$

Finally, we characterize a non-singularist notion of covering. To do so, we first define a new predicate, ' among $^{\circ}$ ':

$$
\mathrm{x} \angle{ }^{\circ} \mathrm{zSS} \equiv{ }_{\text {def }} \exists \mathrm{ys}\left(\mathrm{x} \angle \mathrm{ys} \wedge \mathrm{ys} \angle^{*} \mathrm{zss}\right) \quad \mathrm{x} \text { is } \text { among }^{\circ} \text { the zss }
$$

Then we need a notion of part, corresponding to the intuitive sense under which we say that something material has parts. In $\S 4.2$, we saw that classical mereology is extensional (any two things that have the same parts must be identical), and that this leads one to identify wood and furniture in a situation in which they have the same parts. Our solution to this difficulty is to adopt weaker versions of the axioms (64), (65) and (66), turning them into axiom schemata relative to mass nouns:

$$
\begin{array}{llr}
\text { (82) } & \mathrm{Mx} \wedge \mathrm{My} \wedge \mathrm{x} \leq \mathrm{y} \wedge \mathrm{y} \leq \mathrm{x} \rightarrow \mathrm{x}=\mathrm{y} & \text { M-antisymmetry } \\
\text { (83) } & \mathrm{Mx} \wedge \mathrm{My} \wedge \mathrm{Mz} \wedge \mathrm{x} \leq \mathrm{y} \wedge \mathrm{y} \leq \mathrm{z} \rightarrow \mathrm{x} \leq \mathrm{z} & \text { M-transitivity } \\
\text { (84) } & \mathrm{Mx} \wedge \mathrm{My} \wedge \neg(\mathrm{y} \leq \mathrm{x}) \rightarrow \exists \mathrm{z}(\mathrm{Mz} \wedge \mathrm{z} \leq \mathrm{y} \wedge \neg \text { Ozx) }
\end{array}
$$

This makes the relation of mereological part extensional only with respect to a given mass noun (e.g., instances of wood that have the same wooden parts are identical). But it does not lead to the identification of wood and furniture. In addition, since we do not think that unrestricted mereological sums exist, we do not adopt the axiom schema (67). On the contrary, we take it that a thing that counts as $\mathrm{M}$ must be self-connected, of a single piece: ${ }^{30}$
(85) $\quad \mathrm{Mx} \rightarrow$ self-connected(x)
Self-connectedness

Thus, the greatest portion of wine in a bottle is a thing that counts as wine. So is the greatest portion of wine in the lower half of the bottle. But consider now two bottles of wine. What we have in the two bottles are two things that count as wine, not a disconnected thing that would count as wine. ${ }^{31}$

A covering is then a "plurality of pluralities", as characterized below.

speaker is referring to). The notion of covering should then also be modified. We see no reason for all this presently, hence our choice.

${ }^{29}$ Remark: The predicate 'Q' need not apply collectively to the as. To see why, consider the mass noun silverware, and imagine a circumstance in which the silverware present in the universe of discourse consists in four sets of silverware. Three of them cost a hundred euros, while the fourth one costs fifty euros. Since there is some silverware that costs a hundred euros, the principle of superplural comprehension ensures that there are some things, the as, which satisfy the formal condition in (80). They are what the expression the silverware that costs a hundred euros denotes. In this circumstance, it would be rather peculiar if these things also cost a hundred euros altogether!

${ }^{30}$ This notion must be strong enough, so that two objects that are merely in external contact are not deemed to be connected in the sense that is relevant here. See Casati \& Varzi (1999). They argue that the notion of self-connectedness cannot be reduced to that of part, and that both must be recognized as primitives.

${ }^{31}$ We find the assumption of self-connectedness extremely plausible from a cognitive standpoint. Adopting it also helps to make our account more concrete. However, doing so is not strictly necessary: it suffices for our account to have bite that, in some cases at least, mass nouns may be used to refer to several things at once. 
(86) Non-singularist notion of covering for a mass noun $M$

The css are an M-covering of the as just in case the following three conditions are satisfied:

i) Any thing among ${ }^{\circ}$ the css is M:

y $\angle{ }^{\circ}$ css $\rightarrow$ My

ii) For any "plurality" of the css, no two members of the "plurality" overlap:

$\mathrm{xs} \angle \mathrm{css} \rightarrow \neg(\exists \mathrm{u} \exists \mathrm{v}(\mathrm{u} \angle \mathrm{xs} \wedge \mathrm{v} \angle \mathrm{xs} \wedge \mathrm{u} \neq \mathrm{v} \wedge$ Ouv $))$

iii) For anything v, v overlaps some thing among ${ }^{\circ}$ the css just in case v overlaps one of the as:

$\exists \mathrm{y}\left(\mathrm{y} \angle{ }^{\circ} \operatorname{css} \wedge\right.$ Ovy $) \leftrightarrow \exists \mathrm{w}(\mathrm{w} \angle \mathrm{as} \wedge \mathrm{Ovw})$

Condition i) specifies that the mass noun must apply to each thing in the covering. Imagine the following piece of furniture: a table $t$, which is made of a central leg $l$ that supports a plank p. $t$ admits only one furniture-covering, namely $t$ itself. $l$ and $p$ would not constitute a furniture-covering of $t$, since $l$ is not furniture (and neither is p). By contrast, take the greatest portion of wine in a bottle, $b$. The greatest portion of wine in the lower half of the bottle, $f$, is also wine. And so is the greatest portion of wine in the upper half of the bottle, g. Thus, $f$ and $g$ satisfy the condition and are a possible wine-covering of $b$.

Condition ii) indicates that, for each "plurality" of the covering, the members of the "plurality" must be non-overlapping. Consider again our bottle of wine, with $b, f$, and $g$ as specified. $b$, $f$, and $g$ form a "plurality", hence also a "superplurality" containing a single "plurality" formed of b, $f$, and g. But since b and f overlap (and so do b and g), condition ii) is violated and this "superplurality" is not a possible wine-covering of $b$.

Condition iii) says that the css "make up" the as. ${ }^{32}$ Thus, the "superplurality" whose two "pluralities" are $f$ and $g$ is a wine-covering of $b$ (anything that overlaps $b$ overlaps $f$ or $g$ ). But $f$ is not by itself a wine-covering of $b$ (a strict part of $g$ overlaps $b$, but not $f$ ).

This notion of covering allows us to specify the truth-conditions of various kinds of sentences.

(87) This is M.

When uttering this sentence, the speaker is referring to one or several things at once. Let the as be what the speaker is referring to. The sentence is true just in case $M$ applies to the as. Given distributed reference, this is true just in case each of the as is $\mathrm{M}$ :

Mas $\leftrightarrow \forall \mathrm{x}(\mathrm{x} \angle \mathrm{as} \rightarrow \mathrm{Mx})$

\footnotetext{
${ }^{32}$ Condition iii) generalizes the condition used by Gillon to the case of things that do not have a mereological sum. Using plural logic instead of sets, Gillon's condition may indeed be expressed thus. The gs are a "singularist" covering of the fs just in case the mereological sum of the gs is identical with the mereological sum of the fs.
} 
A condition for the sentence to be truth-valuable is that this $M$ have a (non-empty) denotation, the $\mathrm{M}$ that the speaker intends to refer to. ${ }^{33}$ The interpretation of the sentence then depends on the choice of a covering of this denotation. Let the as be the denotation of this $M$. Let the css be the chosen covering of the as, satisfying condition (86) above. The sentence is true just in case:

ys $\angle^{*}$ css $\rightarrow$ Pys

As an example, consider the sentence:

(89) This silverware costs a hundred euros.

Suppose that what is demonstrated consists in several pieces of silverware, the as. Imagine that the covering has a single "component", the as themselves. Then the sentence is true, relative to this choice of covering, if all the silverware, taken together, costs a hundred euros. This is the collective construal of the sentence. Alternatively, imagine a covering whereby the silverware is divided into two sets, each set containing four pieces of silverware. Then the sentence is true, relative to this choice of covering, if each set of silverware costs a hundred euros. This is a non-collective construal.

(90) The M that Qs Ps.

A condition for the sentence to be truth-valuable is that the expression the $M$ that $Q s$ have a (non-empty) denotation, the as, satisfying condition (80) above. ${ }^{34}$ The interpretation of the sentence then depends on the choice of a covering of this denotation, satisfying condition (86). Let the css be the chosen covering. The sentence is true just in case:

ys $\angle^{*}$ css $\rightarrow$ Pys

This yields a satisfactory result notably with the sentence:

(91) The gold on the table weighs seven ounces.

Bunt (1985: 40) thought that this kind of example could not be dealt with by a semantics that associates to a mass noun a set of instances of $\mathrm{M}$ (cf. §7.1below). Now, in one respect, the non-singularist semantics we are advocating is not extremely far from a set-theoretic account. It associates to a mass noun, not a set of things, but some things, each of which is M. Yet, it has no problem with the above sentence. The denotation of the expression the gold on the table, the as, comprises any things that are gold on the table. For concreteness, suppose there are three solid bits of gold on the table. The denotation of the expression comprises them, as well as many of their parts. The interpretation of the sentence is then relative to the choice of a covering of this denotation. The sentence says, of each "plurality" of this covering, that the things that make up this "plurality"

\footnotetext{
${ }^{33}$ Following Kaplan (1989), we assume that when a sentence containing a demonstrative description is uttered, the utterance is felicitous only if the description is satisfied. So the denotation of a demonstrative description is the objects that the speaker intends to refer to, provided these objects satisfy the non-indexical part of the description. For instance, the denotation of this furniture in a given utterance may be two objects, provided these objects are some furniture. (For a different view, see Corblin (1987).)

${ }^{34}$ With Strawson (1950), we assume that when a sentence containing a definite description is uttered, the utterance is felicitous only if the description is satisfied.
} 
weigh seven ounces together. One construal is extremely salient. It is obtained when the covering contains only one "plurality", whose elements are the three solid bits of gold that are on the table. The sentence then says that these solid bits of gold weigh seven ounces together.

The truth-conditions just given may also be extended to the case of a sentence containing two mass nouns, $M$ and $N$, and a transitive verb $P$ :

(92) The $M$ that Qs Ps the $\mathrm{N}$ that Rs.

A condition for the sentence to be truth-valuable is that the expressions the $M$ that $Q s$ and the $N$ that $R s$ have (non-empty) denotations. Let these be the as and the bs respectively, each satisfying a condition of the kind indicated in (80). The interpretation of the sentence then depends on the choice of a covering of each denotation. Let the css be the chosen M-covering of the as, and the dss, the chosen $\mathrm{N}$-covering of the bs. The sentence is true just in case the following two conditions are satisfied:

ys $\angle^{*}$ css $\rightarrow \exists$ zs $\left(\mathrm{zs} \angle^{*}\right.$ dss $\left.\wedge \mathrm{P}(\mathrm{ys}, \mathrm{zs})\right)$

$\mathrm{zs} \angle^{*}$ dss $\rightarrow$ yss $\left(\mathrm{ys} \angle^{*} \operatorname{css} \wedge \mathrm{P}(\mathrm{ys}, \mathrm{zs})\right)$

This applies in the following case:

(93) The livestock carried the furniture.

Relative to chosen coverings, css and dss, the sentence is true just in case these conditions are satisfied:

- for any livestock ys among the css, there is some furniture zs among the dss such that the ys carried the zs;

- for any furniture zs among the dss, there is some livestock ys among the css such that the ys carried the zs.

Thus, it may be that some pieces of furniture were repeatedly part of the furniture carried by some of the livestock.

The account also applies here:

(94) The wine in the lower half of this bottle is part of the wine in these two bottles.

Mass nouns may refer to several things at once. Therefore, it is plausible to suppose that the relation the expression part of denotes when it is flanked by mass nouns is the same as the relation it denotes when it is flanked by plurals, namely, the among relation ' $\angle$ ' between "pluralities". Now, let the as be the denotation of the expression the wine in the lower half of this bottle, and the bs the denotation of the expression the wine in these two bottles. Relative to chosen coverings, css and dss, the sentence is true just in case the following two conditions are satisfied:

ys $\angle^{*} \mathrm{css} \rightarrow \exists \mathrm{zs}\left(\mathrm{zs} \angle^{*}\right.$ dss $\wedge$ ys $\left.\angle \mathrm{zs}\right)$

$\mathrm{zs} \angle^{*}$ dss $\rightarrow \exists$ ys (ys $\angle^{*}$ css $\wedge$ ys $\angle$ zs)

The sentence is true in particular relative to the following choice of coverings. Call $\mathrm{f}$ the greatest portion of wine in the lower half of this bottle, $g$ the greatest portion of wine in the upper half of this bottle, and $h$ the greatest portion of wine in the other bottle. The covering of the as contains a single "plurality", which has $f$ as sole member. The covering of the bs contains a single "plurality", which has $f, g$, and $h$ as members. The conditions just given are then satisfied since $f$ is among $\mathrm{f}, \mathrm{g}$, and $\mathrm{h}$. 
(95) A lot of M Ps.

The sentence is true just in case there are some xs satisfying the following conditions:

- Mxs $\wedge$ a-lot-of(xs, c), where $c$ is the context of utterance (the interpretation of a lot of is contextually dependent, hence the presence of this parameter of context);

- there exists a covering of the xs, the zss, and:

- $\forall$ ys (ys $\angle^{*}$ zss $\rightarrow$ Pys)

(96) Some M Ps.

The sentence is true just in case:

$\exists y s$ (Mys $\wedge$ Pys)

(97) All M Ps.

Let the ds be the denotation of the mass noun $M$. The interpretation of the sentence is relative to the choice of a covering of this denotation. A collective interpretation is not possible, so this covering must contain at least two "pluralities" (say ys 1 and ys 2 ). Let the css be the chosen covering of the ds. The sentence is true just in case:

ys $\iota^{*}$ css $\rightarrow$ Pys

Consider an example from Roeper:

(98) All phosphorus is either red or black.

Roeper (1983) found this kind of example problematic for various approaches to the semantics of mass nouns, including set-theoretic approaches. In the present account, the sentence is made true by a covering that is a partition of all the phosphorus (i.e., a covering no elements of which overlap), such that the phosphorus in each "component" of this partition (a certain "plurality of things" in each case) is either (wholly) red or (wholly) black.

\subsection{Substances and identity over time}

In this section, we consider how time can be added to our semantics, which is tenseless. This is relevant since, as stressed by Cartwright (1965), we can talk of the identity over time of substances in a variety of ways: ${ }^{35}$

(99) The gold that John dug now makes up those rings.

(100) The coffee that was in that bowl is the coffee that is now in these cups.

\footnotetext{
${ }^{35}$ The notion of substance or matter is linked to that of an ordinary object (on various debates concerning their relationship, see for instance Cartwright (1965), Zimmerman (1995), and Hawley (2001)). Gold, silver, and clay are paradigmatic examples of substances. Oil, water, and wine are liquids, which are also typically seen as substances. Ordinary objects include artifacts like chairs, statues, and rings, organisms like persons, cats, and dolphins, and material bodies like rocks, mountains, and moons. In some cases, an ordinary object may be said to be made up, or constituted by, some or several substances. Thus, a chair may be made of wood, a statue of clay, and a ring of gold. A ring might also be made up of both gold and silver. An organism, however, will usually not be said to be made up of one or several substances. Rather, it will be said to be made up of smaller units like cells.
} 
(101) The clay that was on the desk on July $1^{\text {st }}$ is identical with the clay that was on the table on July $2^{\text {nd }}$.

(Context of utterance: three solid bits of clay were on the desk on July $1^{\text {st }}$, and two solid bits of clay were on the table on July $2^{\text {nd }}$.)

Several temporal frameworks may be used for our purposes. Here we basically follow Simons $(1987, \mathrm{ch} .5, \S 2)$. The main idea is to add a temporal parameter to a tenseless formula when required. (Logical notions like identity, quantification and 'among' relations remain tenseless for us.) Thus, where previously we wrote 'Pc', meaning that $\mathrm{c}$ Ps, we now write ' $\mathrm{P}_{\mathrm{t}} \mathrm{c}$ ', meaning that $\mathrm{c}$ Ps at time $\mathrm{t}$. The truthconditions laid out in (92) for sentences containing two definite mass noun phrases now apply as follows to a sentence like (101). As previously, we use plural constants to specify the denotations of noun phrases, and superplural constants to specify coverings. We also use constants to specify particular times. Thus, let $t$ correspond to July $1^{\text {st }}$, and $u$ to July $2^{\text {nd }}$. Let the denotation of the expression the clay that was on the desk on July $1^{\text {st }}$ be the as. They satisfy condition (80) with time added: ${ }^{36}$

$\mathrm{v} \angle$ as $\leftrightarrow \exists \mathrm{zs}\left(\mathrm{v} \angle \mathrm{zs} \wedge\right.$ clay $_{\mathrm{t}}(\mathrm{zs}) \wedge$ on-the-desk $\left.\mathrm{t}_{\mathrm{t}}(\mathrm{zs})\right)$

Similarly for the clay that was on the table on July $2^{\text {nd }}$, let the bs be their denotation. They satisfy the condition:

$\mathrm{v} \angle \mathrm{bs} \leftrightarrow \exists \mathrm{zs}\left(\mathrm{v} \angle \mathrm{zs} \wedge\left(\right.\right.$ clay $\left._{\mathrm{u}} \mathrm{zs}\right) \wedge$ on-the-table $\left.\mathrm{u}(\mathrm{zs})\right)$

Let the css be the chosen covering of the as, and the dss the chosen covering of the bs. Given the meaning of to be identical, it is only individual things that can be claimed to be identical or different. So any coverings making sentence (101) true will be such that the following two conditions are satisfied:

$\mathrm{y} \angle{ }^{\circ} \operatorname{css} \rightarrow \exists \mathrm{z}\left(\mathrm{z} \angle{ }^{\circ}\right.$ dss $\left.\wedge \mathrm{y}=\mathrm{z}\right)$

$\mathrm{z} \angle^{\circ}$ dss $\rightarrow \exists \mathrm{y}\left(\mathrm{y} \angle{ }^{\circ} \operatorname{css} \wedge \mathrm{y}=\mathrm{z}\right)$

In effect, the sentence will be true when a common covering can be chosen for the as and the bs. This will mean that there are some small bits of clay, each of which has retained its identity over time. On July $1^{\text {st }}$, these bits of clay were so arranged that they made up the as (i.e., they were a covering of the as). On July $2^{\text {nd }}$, they were arranged differently, in such a way that they made up the bs.

\section{Conclusion}

A dilemma put forward by Schein (1993, 2006) and Rayo (2002, 2006) suggests that, in order to characterize the semantics of plurals, we should not use predicate logic, but plural logic, a formal language whose terms may refer to several things at once. In $\S 4$, we showed that a similar dilemma applies to mass nouns. If we use predicate logic and sets, we arrive at a Russellian paradox when characterizing the semantics of mass nouns, just as we do when characterizing the semantics of plurals with the same means. And if we use predicate logic and mereological sums, the semantics turns out to be too weak-for one thing, because the relation of part in classical mereology is extensional, and for another, because predicate logic and mereological sums are not enough to characterize the non-collective construals that sentences containing mass nouns may receive.

\footnotetext{
${ }^{36}$ To simplify formula, we associate to the expression on the desk a non-analyzed predicate. We do likewise for the expression on the table.
} 
We then developed a non-singularist account, where mass nouns are treated as non-singular terms, which may refer to several things at once. In one respect, this treatment is not very far from set-theoretic approaches of mass nouns, which would assign a set of things as the denotation of a mass noun phrase. The non-singular semantics we have proposed assigns some things (rather than a set of things) as the denotation of such a phrase. We therefore showed that some of the main criticisms that have been leveled against set-theoretic approaches could be satisfactorily answered by the non-singularist. The following three kinds of sentences have been seen as presenting difficulties for set theories: ${ }^{37}$

(102) The gold on the table weighs seven ounces.

(103) All phosphorus is either red or black.

(104) The clay that was on the desk on July $1^{\text {st }}$ is identical with the clay that was on the table on July $2^{\text {nd }}$.

We provided a semantics for each in $\S 5$. In each case, the key to resolving the difficulty lied in employing an appropriate notion of covering. A notion of this kind was used by Gillon (1992) to develop a semantics of mass nouns that treats them as singular terms. We generalized the notion so that it may apply to the case of things that do not have a mereological sum. This allowed us to devise a semantics where mass nouns may refer to several things at once, while dealing satisfactorily with the three difficulties just mentioned. This semantics is faithful to the intuition that, if there are eight pieces of silverware on a table, the speaker refers to eight things at once when he says

(105) The silverware that is on the table comes from Italy

and that in this particular case, he might just as well have said

(106) The pieces of silverware that are on the table come from Italy.

\section{Appendix: A brief overview of former approaches to the semantics of mass nouns}

There are two basic approaches to the semantics of mass nouns (cf. Bunt 1985, Nicolas 1997, Pelletier \& Schubert 2003). One uses sets as their semantic values, the other uses mereological sums. We indicate some problems for each approach below.

\subsection{The set-theoretic approach}

The set-theoretic approach to the semantics of mass nouns (e.g., Strawson 1959, Cartwright 1965, and Laycock 1972) treats them as predicates. The sentence

\section{(107) This is wine}

is true if and only if $\mathrm{I}($ this $) \in \mathrm{I}$ (wine), where $\mathrm{I}$ is the interpretation function, $\mathrm{I}($ this $)$ is what is demonstrated, and I(wine) is the set of everything that can be said to be wine.

The question is then how to treat mass nouns in definite descriptions, as in (108) The gold on the table weighs fifty grams.

If the description denotes the set having for element anything that is gold on the table, then how can we evaluate the truth of the sentence? It would not do to give

\footnotetext{
${ }^{37}$ Sentences like (103) are also problematic for mereological approaches to the semantics of mass nouns; cf. $\$ 7.2$ below.
} 
the sum of all weights (cf. Bunt 1985: 41). So we must impose restrictions on the elements of the set $\mathrm{I}$ (the gold on the table).

Now comes a second difficulty concerning identity over time. Consider:

(109) The clay that was on the desk on July $1^{\text {st }}$ is identical with the clay that was on the table on July $2^{\text {nd }}$.

Context of utterance: three solid bits of clay were on the desk on July $1^{\text {st }}$, and two solid bits of clay were on the table on July $2^{\text {nd }}$.

(Example inspired by Cartwright 1965.)

Which set could make $\mathrm{I}\left(\right.$ the clay that was on the desk on July $\left.1^{\text {st }}\right)=\mathrm{I}($ the clay that was on the table on July $2^{\text {nd }}$ ) true?

What about the set of all minimal parts of clay, i.e., the set of all the instances of clay that have no other instance of clay as part? However, with mass nouns like garbage, it is not clear what the minimal parts would be (cf. Pelletier $\&$ Schubert 2003). Moreover, mass nouns like time and space do not seem to have minimal parts. So the semantics of mass nouns should not require them to have some (cf. Bunt 1985).

Finally, according to Roeper (1983), another difficulty appears with universally quantified statements:

(110) All phosphorus is either red or black.

On the set-theoretic approach, this is naturally rendered as

(111) $\mathrm{x} \in \mathrm{I}$ (phosphorus) $\rightarrow \mathrm{x} \in \mathrm{I}$ (either-red-or-black)

But presumably, when the English sentence is true, we may be able to talk of some phosphorus that is partly red and partly black. This phosphorus cannot belong to I(either-red-or-black).

\subsection{The mereological approach}

The mereological approach to the semantics of mass nouns (e.g., Quine 1960, Burge 1972, and Link 1983) focuses first on mass nouns in definite descriptions. When $M$ is a mass noun, it takes the definite noun phrase the $M$ that $Q s$ to refer to the mereological sum of everything that is some $\mathrm{M}$ that Qs. It is such a sum that is weighted in sentence (108), and whose identity over time is asserted in (109).

But (107) must still be dealt with. The proposal is this. This is wine is true if and only if $\mathrm{I}($ this $) \leq \mathrm{I}$ (wine), where $\leq$ is the relation of mereological parthood, $\mathrm{I}($ this $)$ is what is demonstrated, and $\mathrm{I}$ (wine) is the mereological sum of everything that is wine. This yields a new problem with minimal parts. An atom of hydrogen is not water, though it is part of a molecule of $\mathrm{H} 2 \mathrm{O}$. More strikingly, a leg of a chair is not furniture, though it is part of a chair, and a chair is some furniture (Bunt 1985).

Sentence (110) is also problematic on the mereological approach. It should be true if any part of the mereological sum of all the phosphorus is either red or black. But this universal condition is violated by anything that is the mereological sum of some black phosphorus and some red phosphorus.

Moreover, sentences containing mass nouns are liable to collective and non-collective construals (cf. Gillon 1992). Thus,

(112) This silverware costs a hundred euros

may be true if the silverware costs, altogether, a hundred euros (collective construal). It may also be true if the silverware demonstrated consists in two sets 
of silverware, each set costing a hundred euros (non-collective construal). To capture these construals, a notion of covering akin to that proposed by Gillon is needed, and to express this notion, the apparatus of sets, or something as expressive, is required: mereological sums are not enough. Gillon's approach is thus mixed, using mereological sums for the denotation of mass noun phrases, but using sets for coverings.

The mereological approach faces an additional, independent problem. In a given circumstance, it may be that the mereological sum of the $\mathrm{M}$ is identical with the sum of the $\mathrm{N}$ (where $M$ and $N$ are two mass nouns), yet the sentences The $M Q s$ and The $N Q s$ have, intuitively, opposite truth-values. Thus, suppose that some wood of a given kind (e.g., some elm) is used to make furniture of different styles. Then intuitively, the sentence

(113) The furniture is heterogeneous

is true, while

(114) The wood is heterogeneous

is false. But furniture and wood have the same sum (since the relation of mereological part is usually taken to be extensional), so the theory predicts that (113) and (114) should have the same truth-value.

\section{References}

Boolos, G. (1984). To be is to be a value of a variable (or to be some values of some variables). Journal of Philosophy 81, 430-449

Bunt, H. C. (1985). Mass terms and model-theoretic semantics. (Cambridge: Cambridge University Press)

Burge, T. (1972). Truth and mass terms. Journal of Philosophy 69, 263-282

Cartwright, H. (1965). Heraclitus and the bath water. Philosophical Review 74, 466-485

Casati, R. \& A. Varzi. (1999). Parts and places. The structures of spatial representation. (Cambridge: MIT Press)

Chierchia, G. (1998). Plurality of mass nouns and the notion of "semantic parameter". (In S. Rothstein (Ed.), Events and grammar (pp. 53-103). Dordrecht: Kluwer Academic Publishers.)

Corbett, G. (2000.) Number. (Cambridge: Cambridge University Press)

Corblin, F. (1987). Indéfini, défini et démonstratif. (Geneva: Droz)

Farkas, D. \& H. de Swart. (2007). Inclusive and exclusive plurals reconciled. (In M. Aloni, P. Dekker \& F. Roelofsen (Eds.), Proceedings of the 16th Amsterdam Colloquium. Palteam.)

Gillon, B. S. (1990.) Bare plurals as plural indefinite noun phrases. (In H. E. Kyburg Jr. et al (Eds.), Knowledge representation and defeasible reasoning (pp. 119-166). Dordrecht: Kluwer Academic Publishers.)

Gillon, B. S. (1992). Towards a common semantics for English count and mass nouns. Linguistics and Philosophy 15, 597-639

Gillon, B. S. (1996). Collectivity and distributivity internal to English noun phrases. Language Sciences 18, 443-468

Glanzberg, M. (2004). Quantification and realism. Philosophy and Phenomenological Research 69, 541-572

Hawley, K. (2001). How things persist. (Oxford: Clarendon Press)

Kaplan, D. (1989). Demonstratives. (In J. Almog, J. Perry \& H. Wettstein (Eds.), Themes from Kaplan (pp. 481-563). New York: Oxford University Press.)

Krifka, M. (1991). Massennomina. (In A. von Stechow \& D. Wunderlich (Eds.), Semantik, ein internationales Handbuch (pp. 399-417). Berlin: de Gruyter.) 
Krifka, M., Pelletier, F. J., Carlson, G. N., Chierchia, G., Link, G., \& A. ter Meulen. (1995). Introduction to genericity. (In G. N. Carlson \& F. J. Pelletier (Eds.), The generic book (pp. 1-124). Chicago: Chicago University Press.)

La Palme-Reyes, M., Macnamara, J. \& Reyes, G. E. (1994). Reference, kinds and predicates. (In J. Macnamara \& G. E. Reyes (Eds.), The logical foundations of cognition (pp. 91-145). Oxford: Oxford University Press.)

La Palme-Reyes, M., Macnamara, J., Reyes, G. E. \& Zolfaghari, H. (1999). Count nouns, mass nouns, and their transformations: a unified category-theoretic semantics. (In R. Jackendoff, P. Bloom \& K. Wynn (Eds.), Language, logic and concepts (pp. 427-452). Cambridge: MIT Press.)

Laycock, H. (1972). Some questions of ontology. Philosophical Review 81, 3-42

Lewis, D. (1991). Parts of classes. (Oxford: Oxford University Press)

Link, G. (1983). The logical analysis of plurals and mass terms: a lattice-theoretical approach. (In R. Bauerle, C. Schwartze, \& A. von Stechow (Eds.), Meaning, use and interpretation of language (pp. 302-323). Berlin: Mouton de Gruyter.)

Linnebo, Ø. (2008). Plural quantification. (In E. N. Zalta (Ed.), The Stanford Encyclopedia of Philosophy (Spring 2008 Edition). Retrieved from http://plato.stanford.edu/archives/spr2008/entries/plural-quant/)

Linnebo, Ø. \& D. Nicolas. (2008). Superplurals in English. Analysis 68(3), 186-197

McKay, T. (2006). Plural predication. (Oxford: Oxford University Press)

Nicolas, D. (1997, unpublished). Count nouns, mass nouns and their acquisition. Retrieved from http://d.a.nicolas.free.fr/research/Nicolas.MN.CN.Acquisition.pdf

Nicolas, D. (2002a). La distinction entre noms massifs et noms comptables. Aspects linguistiques et conceptuels. (Louvain: Éditions Peeters)

Nicolas, D. (2002b, unpublished.) Conversions of count nouns into mass nouns in French: the roles of semantic and pragmatic factors in their interpretations. Retrieved from http://d.a.nicolas.free.fr/research/Nicolas-Conversions.pdf

Oliver, A. \& T. Smiley. (2001). Strategies for a logic of plurals. Philosophical Quarterly 51, 289-306

Oliver, A. \& T. Smiley. (2006). A modest logic of plurals. Journal of Philosophical Logic 35, 317-348

Parsons, T. (1970). An analysis of mass and amount terms. Foundations of Language 6, 363-388

Pelletier, J. F. \& N. Asher. (1997). Generics and defaults. (In J. van Benthem, \& A. ter Meulen (Eds.), Handbook of logic and language (pp. 1125-1177). Amsterdam: Elsevier Science.)

Pelletier, J. F. \& L. Schubert. (2003). Mass expressions. (In D. Gabbay \& F. Guenthner (Eds.), Handbook of philosophical logic, $2^{\text {nd }}$ edition, Volume 10 (pp. 249-336). Dordrecht: Kluwer Academic Publishers.)

Quine, W. V. O. (1960). Word and object. (Cambridge: MIT Press)

Rayo, A. (2002). Word and objects. Noûs 36, 436-464

Rayo, A. (2006). Beyond plurals. (In A. Rayo, \& G. Uzquiano (Eds.), Absolute generality (pp. 220-254). Oxford: Oxford University Press.)

Rayo, A. \& G. Uzquiano (Eds.). (2006a). Absolute generality. (Oxford: Oxford University Press)

Rayo, A. \& G. Uzquiano. (2006b). Introduction. (In A. Rayo, \& G. Uzquiano (Eds.), Absolute generality (pp. 1-19). Oxford: Oxford University Press.)

Roeper, P. (1983). Semantics for mass terms with quantifiers. Noûs 17, 251-265

Sauerland, U., Andersen, J. \& K. Yatsushiro. (2005) The plural is semantically unmarked. (In S. Kepser \& M. Reis (Eds.), Linguistic evidence. Berlin: Mouton de Gruyter.)

Schein, B. (1993). Plurals and events. (Cambridge: MIT Press)

Schein, B. (2006). Plurals. (In E. Lepore \& B. Smith (Eds.), Handbook of philosophy of language (pp. 716-767). Oxford: Oxford University Press.) 
Schwarzschild, R. (1996). Pluralities. (Dordrecht: Kluwer Academic Publishers)

Simons, P. (1982). Plural reference and set theory. (In B. Smith (Ed.), Parts and moments: studies in logic and formal ontology, pp. 113-159. Munich: Philosophia Verlag.)

Simons, P. (1987). Parts. A study in ontology. (Oxford: Oxford University Press)

Simons, P. (1997). Bolzano on collections. Grazer Philosophische Studien 53, 87-108

Strawson, P. F. (1950). On referring. Mind 59, 320-344

Strawson, P. F. (1959). Individuals. An essay in descriptive metaphysics. (London: Methuen)

Uzquiano, G. (2006). The price of universality. Philosophical Studies 129, 137-169

van Inwagen, P. (1990). Material beings. (Ithaca: Cornell University Press)

van Inwagen, P. (1994). Composition as identity. Philosophical Perspectives 8, 207-220

Varzi, A. (2000). Mereological commitments. Dialectica 54, 283-305

Varzi, A. (2006). Mereology. (In E. N. Zalta (Ed.), The Stanford encyclopedia of philosophy (winter 2006 edition). Retrieved from http://plato.stanford.edu/archives/win2006/entries/mereology)

Williamson, T. (2003). Everything. Philosophical Perspectives 17, 415-465

Yi, B.-Y. (1999). Is mereology ontologically innocent? Philosophical Studies 93, 141160

Yi, B.-Y. (2005). The logic and meaning of plurals. Part I. Journal of Philosophical Logic 34, 459-506

Yi, B.-Y. (2006). The logic and meaning of plurals. Part II. Journal of Philosophical Logic 35, 239-288

Zimmerman, D. W. (1995). Theories of masses and problems of constitution. Philosophical Review 104, 53-110 